polymorphisms and problems of multiple loci. The clarity with which mathematical aspects of these topics are presented make these chapters the most successful presentation of this complicated information that is currently available.

The second edition differs from the first in that the section on chromosome aberrations has been expanded and descriptions of the techniques of somatic cell hybridization and nucleic acid hybridization which provide evidence of synteny of gene loci are included. The special problem of allelism is discussed in depth, emphasizing the complexity of gene loci.

Recent advances in the field of human genetics have revealed the underlying biological and biochemical defects of many genetically determined diseases, the causes of which have been obscure for many years - thus opening up the possibility of diagnosis and treatment. A fundamental understanding of human genetics is now an essential requirement of modern clinical practice and this text book is an accurate and enjoyable source of information on the subject.

\section{Towards the Prevention of Fetal Malformation}

Edited by J. B. SCrimgeour. Pp. 301, illustrated. Edinburgh University Press, 1978. £12.00.

This book is based on papers presented at a symposium held in Edinburgh in March 1977 and contains twenty-two chapters prepared by distinguished obstetricians, geneticists and physicians on medical, ethical and administrative problems of prenatal diagnosis of congenital disease. Many of the contributors, as advisors to the Department of Health, are influential in the forward planning of genetic services to the community, and concerned with the implementation of antenatal screening on a national basis. This book is an attempt to produce a statement of the possibilities of preventing congenital disease by carefully evaluating methods of diagnosis for their accuracy, safety and cost benefit. It also assesses the potential effect of prenatal screening programmes on the quality of life of the families at risk of genetically determined disease.

The topics for discussion are divided into several sections namely, challenge, aetiology, diagnosis, management, costs, implications and future. Under the heading of 'challenge' Professor Galjaard outlines the need for national concern and education of the medical profession and public alike. Dr Brock puts the case for population screening for neural tube defects supported by data from the U.K. collaborative study 1977, and Professor Passarge describes the indications for selective screening of high risks groups.

The section on 'aetiology' is more up to date than many paediatric text books. For example, Dr Evans discusses the Seveso affair in a chapter on environmental hazard and $\mathrm{Dr}$ Eva Alberman discusses the teratogenicity of fertility drugs. Other valuable contributions in this section describe the effect of chromosome malsegregation (Professor Boue) virus infections (Professor Hurley) and drug therapy (Sir Derrick Dunlop) on embryogenesis.

The chapters devoted to 'diagnosis and management' consider the techniques of ultrasound, amniocentesis, amniotic cell culture for biochemical studies, fetal blood sampling and mid-trimester abortion. Problems are clearly stated and carefully analysed but personal preferences and experience is not excluded.

The final chapters on the medical and legal implications and the future of antenatal screening and diagnosis are exceptional in that the issues have not been presented so clearly before. Dr Clive advises obstetricians to avoid litigation, and problems of financing and managing national screening programmes are discussed by Professors Fairweather and Brotherston. Professor Polani in a look into the future defines areas for new research and foresees a major role for the molecular biologist in diagnosis, treatment and management of genetic disease in the years to come.

There is no doubt that the editor and his publishers have provided a valuable service in transposing what must have been a lively and stimulating meeting into a well balanced book. There is obviously a need among obstetricians for this book which includes many important new concepts relevant to clinical practice. Medical students, social workers and medical administrators will also benefit from this book which will enable them to assess for themselves the scope of preventing congenital disease.

\title{
Notice
}

\section{INTERNATIONAL SYMPOSIUM ON FIBRINOLYSIS WITH UROKINASE}

\author{
A Serono Research Foundation Symposium, Europe, Inc. \\ April 5-7, 1979, Hinterzarten/Freiburg, Germany
}

The first International Symposium on Fibrinolysis with UROKINASE will be held at Hinterzarten, near Freiburg (Black Forest), from April 5-7, 1979. Prof. V. Tilsner, Hamburg (Chairman), and Prof. G. P. McNicol, Leeds, have assumed the scientific organization.

Address correspondence to:

Prof. Dr. med. V. Tilsner, Abteilung für Blutgerinnungsstörungen Chir. Univ.-Klinik Eppendorf, Martinistraße 52, D-2000 Hamburg 20. 